\title{
PENENTUAN NILAI EMISIVITAS WARNA MENGGUNAKAN PENERANGAN PADA MINIATUR RUANG BERBENTUK KUBUS DAN PROSES PEMBELAJARAN FISIKA KELAS X SMK NEGERI 2 BENGKULU TENGAH
}

\section{(Determination of Color Emission Value Using Information on Miniature Space for Cube and Learning Process Physics Class X SMK Negeri 2 Bengkulu Tengah)}

\author{
Cariti Dassa Urra ${ }^{1^{*}}$, A. Mayub ${ }^{2}$, M. Farid ${ }^{3}$ \\ ${ }^{1}$ Mahasiswa Pascasarjana Pend. IPA FKIP Univ. Bengkulu \\ ${ }^{2}$ Dosen Pendidikan Fisika FKIP Univ. Bengkulu \\ ${ }^{3}$ Dosen Jurusan Fisika FMIPA Univ. Bengkulu \\ *caritidassaurra@gmail.com
}

\begin{abstract}
This study aims to: know the value of emissivity of purple, green, blue, red, light green, light blue, orange, yellow, pink, and improvement of learning outcomes by using PBL model on the concept of heat transfer class X TKR SMKN 2 Bengkulu Tengah, and explain the difference of students' cognitive learning outcomes in high, medium and low group. This study deals with the measurement of color emissivity and its implementation in physics learning on the topic of heat transfer. The population in this study is all students of class $X$ SMK Negeri 2 Bengkulu Tengah academic year 2016/2017. The sample is taken by purposive sampling technique, that is class X.TKR (Light Vehicle Technique) which is taught by Problem Based Learning (PBL) model. This research is a quasi experimental research with One Group pretest-posttest design. The results showed that the purple comet value was 0.91 , the green emissivity (going green) was 0.84 , the blue emissivity (true blue) was 0.77 , the red color emissivity (talk of the town) 0.66 , light green color emissivity (apple martini) of 0.61 , blue sky emissivity of 0.54 , orange torch emission of 0,50 , emissivity of light brown (pastry puff) of 0.46 , yellow color emission (absolute yellow) of 0.37 , and pink emissivity (crystal pink) of 0.24 ; There is an increase in learning outcomes on the concept of high, medium and low group high caloric transfer with $\mathrm{N}$-gain values of 0.76 (high), 0.64 (medium), and 0.46 (moderate); There was a difference of students' cognitive learning outcomes in the high, medium and low groups shown by Fcount> Ftable $(4.40>3.35)$ at the $5 \%$ significance level.
\end{abstract}

Keywords: emissivity, color, problem based learning, learning outcome of SMK Negeri 2 Bengkulu Tengah

\footnotetext{
ABSTRAK

Penelitian ini bertujuan untuk: mengetahui nilai emisivitas warna ungu, hijau, biru, merah, hijau muda, biru muda, jingga, coklat muda kuning, merah muda, dan peningkatan hasil belajar dengan menggunakan model PBL pada konsep perpindahan kalor siswa kelas X TKR SMKN 2 Bengkulu Tengah, dan menjelaskan perbedaan hasil belajar kognitif siswa pada kelompok tinggi, sedang dan rendah. Penelitian ini berkaitan dengan pengukuran emisivitas warna serta implementasinya pada pembelajaran fisika pada topik perpindahan kalor. Populasi dalam penelitian ini adalah seluruh siswa kelas $X$ SMK Negeri 2 Bengkulu Tengah tahun pelajaran 2016/2017. Sampel diambil dengan teknik sampling purposive, yaitu kelas X.TKR (Teknik Kendaraan
} 
Ringan) yang diajar dengan model pembelajaran Problem Based Learning (PBL). Penelitian ini adalah penelitian eksperimen semu dengan desain One Group pretest-posttest design. Hasil penelitian menunjukkan bahwa nilai emisivitas warna ungu (purple comet) sebesar 0,91,emisivitas warna hijau (going green) sebesar 0,84, emisivitas warna biru (true blue) sebesar 0,77, emisivitas warna merah (talk of the town) sebesar 0,66, emisivitas warna hijau muda (apple martini) sebesar 0,61, emisivitas warna biru muda (sky blue) sebesar adalah 0,54, emisivitas warna jingga (orange torch) sebesar 0,50, emisivitas warna coklat muda (pastry puff) sebesar 0,46, emisivitas warna kuning (absolute yellow) sebesar 0,37 , dan emisivitas warna merah muda (crystal pink) sebesar 0,24; Terdapat peningkatan hasil belajar pada konsep Perpindahan Kalor siswa kelompok tinggi, sedang dan rendah dengan nilai $\mathrm{N}$ gain maing-masing sebesar 0,76 (tinggi), 0,64 (sedang), dan 0,46 (sedang); Terdapat perbedaan hasil belajar kognitif siswa pada kelompok tinggi, sedang dan rendah yang ditunjukkan oleh $F_{\text {hitung }}>F_{\text {tabel }}(4,40>3,35)$ pada taraf signifikansi $5 \%$.

Kata kunci : emisivitas, warna, problem based learning, hasil belajar SMK Negeri 2 Bengkulu Tengah

\section{PENDAHULUAN}

Emisivitas $(\varepsilon)$ adalah rasio energi yang dipancarkan oleh material tertentu oleh benda hitam (black body) yang ideal pada suhu yang sama (Jin dan liang, 2005). Hal itu merupakan kemampuan suatu benda untuk meradiasikan energi yang diserapnya. Benda hitam sempurna memiliki emisivitas sama dengan $1(\mathrm{e}=1)$ sementara objek sesungguhnya memiliki emisivitas kurang dari satu. Emisivitas adalah satuan yang tidak berdimensi Pada umumnya, semakin kasar dan hitam benda tersebut, emisivitas meningkat mendekati 1.

Penelitian-penelitian tentang pengaruh warna terhadap perpindahan panas telah banyak dilakukan sebelumnya. (Uemoto, 2010) mengatakan bahwa perubahan warna (polos, putih, kuning dan coklat) mempengaruhi perpindahan panas pada atap, dan warna coklat memiliki temperatur luar paling tinggi diantara warna-warna tersebut. Pada eksperimen yang telah dilakukan dia menggunakan lampu sebagai sumber panas. Dan dari hasil eksperimen diketahui bahwa warna coklat memiliki temperatur permukaan tertinggi sebesar $81,7^{\circ} \mathrm{C}$ dibandingkan warna kuning sebesar $69,8^{\circ} \mathrm{C}$ dan warna putih sebesar $57^{\circ} \mathrm{C}$.

Dalam teori warna Daniel dalam Anambyah dan Setyowati (2010) warnawarna cerah akan memantulkan cahaya, sedangkan warna-warna gelap cenderung menyerap cahaya. Menurut Prasasto dalam Anambyah dan Setyowati (2010) dalam Penggunaan bahan-bahan bangunan yang bersifat memantulkan cahaya dan panas atau bahan-bahan yang bersifat menyimpan panas akan menyebabkan meningkatnya temperatur lingkungan (di dalam dan di luar bangunan) (heat-island effect).

Suatu penerangan diperlukan oleh manusia untuk mengenali suatu objek secara visual. Pencahayaan yang baik memungkinkan orang dapat melihat objekobjek yang dikerjakannya secara jelas dan cepat. Hampir kebanyakan pengguna energi komersial dan industri peduli penghematan energi dalam sistem penerangan. Seringkali, penghematan energi yang cukup berarti investasi yang minim dan masuk akal. Menerapkan sistem pencahayaan yang efisien sehingga penggunaan listrik bisa lebih hemat dan sangat menguntungkan. Pasalnya, pencahayaan atau penerangan mengkonsumsi kurang lebih $30 \%$ dari total energi dalam suatu bangunan. Maka konsumsi listrik sebuah lampu merupakan faktor utama untuk memilih solusi pencahayaan. Dengan desain pencahayaan yang baik, penghematan energi jelas sangat berarti (Amin, 2011)

Menghitung nilai emisivitas warna dengan menggunakan media ruang 
berbentuk kubus, dirasa sangat perlu untuk para siswa sekolah. Salah satu cara adalah dengan menggunakan miniatur ruang berbentuk kubus dalam pembelajaran fisika.. Berdasarkan observasi di SMK Negeri 2 Bengkulu Tengah, pada umumnya para siswa mengganggap pelajaran fisika sebagai pelajaran yang sulit dan tidak menarik. Hal ini terjadi karena pelajaran fisika bersifat abstrak, empiris dan matematis sehingga minat dan motivasi siswa sangat kurang. Dari hasil wawancara diketahui bahwa nilai rata-rata ujian fisika siswa kelas $X$ TKR berada dibawah nilai Kriteria Ketuntasan Minimal (KKM) yaitu 75. Pada T.P. 2016/2017 rata-rata nilai UAS Semester Ganjil adalah 60. Data ini menunjukkan bahwa nilai rata-rata ujian fisika kelas $X$ TKR pada sekolah tersebut masih tergolong rendah. Berdasarkan kenyataan tersebut, perlu diterapkan suatu model pembelajaran yang sesuai dan mampu meningkatkan aktivitas dan hasil belajar fisika siswa.

Suparno (2013) mengemukakan dalam pembelajaran fisika yang terpenting adalah siswa yang aktif belajar fisika, maka semua usaha guru harus diarahkan untuk membantu dan mendorong siswa mau mempelajari fisika sendiri. Guru dituntut dapat memilih model pembelajaran yang dapat menumbuhkan semangat setiap siswa untuk secara aktif ikut terlibat dalam pengalaman belajarnya. Salah satu model pembelajaran yang memungkinkan mengembangkan keterampilan berpikir, kemandirian dan percaya diri siswa adalah model Problem Based learning (PBL).

\section{KERANGKA TEORITIS}

Emisivitas berhubungan erat dengan dengan radiasi kalor.Joseph Stefan (18531893) dan Ludwig Boltzmann (1844-1906) mengemukakan hukum yang disebut dengan Hukum Stefan-Boltzmann yang berbunyi:

"Jumlah energi yang dipancarkan persatuan permukaan suatu benda hitam dalam satuan waktu akan berbanding lurus dengan pangkat empat temperatur termodinamikanya"

Hukum Stefan-Boltzmann ini secara matematis ditulis :

$$
I_{\text {total }}=e \cdot \sigma \cdot T^{4}
$$

Intensitas merupakan daya persatuan luas, maka persamaan (1) dapat ditulis sebagai:

$$
\frac{P}{A}=e . \sigma \cdot T^{4}
$$

Besarnya nilai hambatan masingmasing warna dapat digunakan untuk menentukan nilai emisivitas masing-masing warna tersebut. Dengan menganggap bahwa emisivitas warna hitam adalah 1 dan pada kondisi suhu $(T)$ dan luas daerah $(A)$ yang sama, maka besarnya perbandingan nilai hambatan masing-masing warna dapat dituliskan dalam bentuk:

$$
\frac{k \cdot R_{H}}{k \cdot R_{X}}=\frac{\mathrm{e}_{\mathrm{H}} \sigma T_{H}^{4} A}{\mathrm{e}_{\mathrm{X}} \sigma T_{H}^{4} A} \text {. }
$$

(3)

Perbandingan nilai hambatan ini dapat digunakan untuk menentukan emisivitas masing-masing warna. Nilai emisivitas warna hitam $\left(\mathrm{e}_{\mathrm{H}}\right)=1$, maka persamaan emisivitas dapat dituliskan sebagai berikut :

$$
e_{x}=\frac{R_{x}}{R_{H}}
$$

Keterangan :

$\mathrm{R}_{\mathrm{H}}=$ nilai hambatan warna hitam

$\mathrm{R}_{\mathrm{X}}=$ nilai hambatan warna tertentu

$\mathrm{e}_{\mathrm{H}}=$ emisivitas warna hitam

\section{METODE}

$e_{\mathrm{X}}=$ emisivitas warna tertentu

Penelitian yang dilakukan adalah penelitian sains yang bertujuan menentukan nilai emisivitas warna ungu (purple comet), hijau (going green), biru (true blue), merah (talk of the town), hijau muda (apple martini), biru muda (sky blue), jingga (orange torch), coklat muda (pastry puff), kuning (absolute yellow), dan merah muda (crystal pink). Penelitian sains dilakukan di Laboratorium SMK Negeri 2 Bengkulu tengah pada tanggal 16-22 Maret 2017. Penelitian pendidikan dilaksanakan di SMK Negeri 2 Bengkulu tengah pada tanggal 24 - 28 April 2017.

Populasi dalam penelitian ini adalah seluruh siswa kelas $X$ SMK Negeri 2 Bengkulu Tengah tahun pelajaran 
2016/2017. Sampel diambil dengan teknik sampling perposive, yaitu kelas X.TKR (Teknik Kendaraan Ringan) yang diajar dengan model pembelajaran Problem Based Learning (PBL). Penelitian ini adalah penelitian eksperimen semu menggunakan desain one group pretest-posttest design. Rancangan penelitian ditunjukkan pada tabel 1 berikut ini:

Tabel 1 Desain penelitian

\begin{tabular}{|c|c|c|c|}
\hline \multirow{2}{*}{ Subjek } & Pretest & Perlakuan & Posttest \\
\cline { 2 - 4 } & $\mathrm{O}$ & $\mathrm{X}$ & $\mathrm{O}$ \\
\hline
\end{tabular}

Keterangan:

$\mathrm{O}:$ Pretest dan posttest

$\mathrm{X}$ : Penggunaan model Problem Based Learning (PBL)

Variabel bebas dalam penelitian ini adalah model pembelajaran Problem Based Learning, sedangkan variabel terikatnya adalah hasil belajar fisika siswa. Instrumen penelitian terdiri atas perangkat pembelajaran (RPP dan LKS) dan instrumen pengumpulan data (soal pretest dan posttest sebanyak 10 soal). Perangkat pembelajaran digunakan dalam pelaksanaan pembelajaran, Sedangkan instrumen pengumpulan data sebagai alat pengambilan data penelitian. Data penelitian adalah nilai pemahaman konsep (kognitif) yang dikumpulkan dengan teknik tes tertulis dalam bentuk soal pilihan ganda. Sebelum digunakan, semua instrumen tersebut dilakukan uji validitas. Untuk RPP dan LKS hanya dilakukan uji validitas isi oleh satu orang dosen dan dua orang guru fisika. Sedangkan instrument tes kognitif dilakukan uji validitas isi dan reliabilitas (ICC) oleh satu orang dosen dan dua orang guru fisika (sebagai judgment experts). Setelah itu, soal tes kognitif diujikan di lapangan. Hasil yang diperoleh digunakan untuk menguji validitas, reliabilitas, tingkat kesukaran dan daya beda soal. Berdasarkan hasil uji tersebut diperoleh: (1) tes kognitif yang diterima 10 butir dengan realibilitas tinggi $\left(r_{11}=0,78\right)$, (2) sebanyak 5 butir soal tidak valid dan dibuang. Data penelitian ini berupa nilai pemahaman konsep fisika. Data tersebut dianalisis dengan statistik deskriptif dan uji ANAVA. Analisis deskriptif digunakan untuk mendeskripsikan nilai pemahaman konsep fisika pada kelompok tinggi, sedang dan rendah. Sedangkan uji ANAVA untuk pengujian terhadap hipotesis yang telah dirumuskan pada taraf signifikansi $5 \%$. Hipotesis penelitian ini, yaitu: (1) Terdapat peningkatan hasil belajar kognitif pada konsep Perpindahan Kalor siswa kelas $X$ TKR SMK Negeri 2 Bengkulu Tengah kelompok tinggi, sedang dan rendah, dan 2) Terdapat perbedaan hasil belajar kognitif pada konsep Perpindahan Kalor siswa kelas X-TKR SMK Negeri 2 Bengkulu Tengah kelompok tinggi, sedang dan rendah. Hipotesis pertama diuji dengan nilai $\mathrm{N}_{\text {gain. }}$. Hipotesis kedua diuji dengan Uji ANAVA.

\section{HASIL DAN PEMBAHASAN}

Pengukuran nilai hambatan yang digunakan untuk menentukan nilai emisivitas menggunakan multimeter digital dan multimeter analog sebagai validasi. Hasil perhitungan nilai emisivitas dari nilai hambatan yang diukur dengan multimeter analog dapat dilihat pada tabel 2 berikut ini:

Tabel 2. Emisivitas Rata-Rata ${ }^{2}$

\begin{tabular}{|c|l|c|r|}
\hline No & \multicolumn{1}{|c|}{ Warna } & $\begin{array}{c}\text { rata- } \\
\text { rata }\end{array}$ & $\begin{array}{r}\text { Standar } \\
\text { Deviasi }\end{array}$ \\
\hline 1 & Ungu (purple comet) & 0,91 & 0,019 \\
\hline 2 & Hijau (going green) & 0,84 & 0,023 \\
\hline 3 & Biru (true blue) & 0,77 & 0,024 \\
\hline 4 & $\begin{array}{l}\text { Merah (talk of the } \\
\text { town) }\end{array}$ & 0,66 & 0,011 \\
\hline
\end{tabular}




\begin{tabular}{|c|l|c|c|}
5 & $\begin{array}{l}\text { Hijau muda (apple } \\
\text { martini) }\end{array}$ & 0,61 & 0,013 \\
\hline 6 & Biru muda (sky blue) & 0,54 & 0,020 \\
\hline 7 & Jingga (orange torch) & 0,50 & 0,018 \\
\hline 8 & $\begin{array}{l}\text { Coklat muda (pastry } \\
\text { puff) }\end{array}$ & 0,46 & 0,021 \\
\hline 9 & $\begin{array}{l}\text { Kuning (absolute } \\
\text { yellow) }\end{array}$ & 0,37 & 0,013 \\
\hline 10 & $\begin{array}{l}\text { Merah muda (crystal } \\
\text { pink) }\end{array}$ & 0,24 & 0,012 \\
\hline
\end{tabular}

Dari data hasil penelitian ini didapat urutan warna berdasarkan nilai emisivitasnya. Urutan warna yang di dapat yaitu : ungu (purple comet), hijau (going green), biru (true blue), merah (talk of the town), hijau muda (apple martini), biru muda (sky blue), jingga (orange torch), coklat muda (pastry puff), kuning (absolute yellow), dan yang terakhir merah muda (crystal pink). Urutan tersebut terlihat berdasarkan tingkat gelap dan terang suatu warna. Semakin gelap suatu warna maka semakin besar nilai emisivitasnya, sebaliknya semakin terang suatu warna maka semakin kecil nilai emisivitasnya. Hasil penelitian ini sependapat dengan Satwiko (dalam Yohana dkk : 2011) yang menyatakan nilai emisivitas atau absorbsi panas warna gelap lebih besar dibandingkan dengan warna terang sehingga warna gelap cenderung menangkap atau menyimpan panas sedangkan warna terang cenderung memiliki sifat memantulkan panas.

Hasil tersebut didukung oleh IIminnafik (2015) dalam penelitiannya yang berjudul variasi bahan dan warna atap bangunan untuk menurunkan temperatur ruangan akibat pemanasan global menyatakan warna gelap (merah) cenderung menyerap panas lebih besar dibandingkan warna lebih cerah (abu-abu).

Emisivitas tertinggi pada penelitian ini yaitu warna ungu (purple comet) dengan rata-rata emisivitasnya 0,91 dan standar deviasinya 0,019. Rata-rata emisivitas warna hijau (going green) sebesar 0,84 dengan standar deviasinya 0,023, sedangkan nilai emisivitas pada literatur (table of total emissivity OMEGASTOPE ) sebesar 0,92 untuk warna green Cu2O3. Rata-rata emisivitas warna biru (True Blue) sebesar 0,77 dengan standar deviasinya 0,024 , sedangkan nilai emisivitas pada literatur (table of total emissivity OMEGASTOPE ) sebesar 0,78 untuk blue on al foil.

Rata-rata emisivitas warna merah (talk of the town) sebesar 0,66 dengan standar deviasinya 0,011 sedangkan nilai emisivitas pada literatur (table of total emissivity OMEGASTOPE ) sebesar 0,61 ini untuk red on al foil (2 coats). Rata-rata emisivitas warna hijau muda (apple martini) sebesar 0,61 dan standar deviasinya 0,013. Rata-rata emisivitas warna biru muda (sky blue) sebesar 0,54 dan standar deviasinya 0,020. Rata-rata emisivitas warna jingga (orange torch) sebesar 0,50 dengan standar deviasinya 0,018 .

Rata-rata emisivitas warna coklat muda (pastry puff) sebesar 0,46 dengan standar deviasinya 0,021, sedangkan nilai emisivitas pada literatur (table of total emissivity OMEGASTOPE ) sebesar 0,87 untuk warna brown. Rata-rata emisivitas warna kuning (absolute yellow) sebesar 0,37 dengan standar deviasinya 0,013, sedangkan nilai emisivitas pada literatur (table of total emissivity OMEGASTOPE ) sebesar 0,57 untuk yellow on al foil. Ratarata emisivitas warna merah muda (crystal pink) sebesar 0,24 dan standar deviasinya 0,012 .

Terdapat Perbedaan nilai emisivitas ini dapat terjadi karena warna yang peneliti pakai tidak sama dengan warna yang literature pakai serta bahan yang digunakan juga berbeda. Warna yang peneliti gunakan dalam penelitian ini menggunakan warna cat tembok. Perbedaan alat yang digunakan juga sangat berpengaruh. Pada literature, alat yang digunakan adalah omegastope atau 
infrared pyrometers, sedangkan peneliti menggunakan multimeter untuk mencari perbandingan nilai hambatan warna untuk mendapatkan nilai emisivitasnya. Semua laboratorium memiliki alat laboratorium berupa multimeter, sehingga guru fisika dapat mengadopsi penelitian ini untuk memberikan variasi pembelajaran fisika yang lebih baik.

Berdasarkan hasil penelitian yang telah dilakukan, diperoleh bahwa tiap-tiap warna memiliki nilai emisivitas yang berbeda berdasarkan tingkat kegelapan warnanya. Semakin gelap warna semakin besar nilai emisivitasnya. Begitu pula sebaliknya, semakin terang warnanya semakin kecil nilai emisivitasnya. Besar kecilnya nilai emisivitas menunjukkan kemampuan suatu benda/zat menyerap energi panas dari lingkungannya (Lillesand et al., 2008).

Sebagian arsitek mengakui warna merupakan salah satu bentuk komukasi verbal yang menyampaikan sebuah pesan kepada orang lain maupun diri sendiri. Warna menyampaikan sebuah pesan identitas dan menjadi sebuah symbol perasaaan seperti psikologis, motovasi, dan astetika. Selain bisa dipandang dari aspek keindahan, pemilihan warna yang tepat untuk bangunan juga sangat berpengaruh terhadap penyerapan energi radiasi cahaya lampu pada setiap bangunan. Hal ini tentu saja dapat dijadikan sebagai salah satu solusi penghematan listrik pada skala bangunan, yang paling mudah diterapkan pada skala rumah tinggal dengan mempertimbangkan konfigurasi arsitekturalnya, susunan material, dimensi hingga pewarnaan dinding bangunan perlu diperhatikan.

Krisis energi merupakan masalah yang sangat menghawatirkan, berbagai upaya dilakukan untuk mengatasi kemungkinan terjadinya krisis energi salah satunya dengan cara menghemat listrik. Pemilihan warna cat tembok ruangan menjadi salah satu yang mempengaruhi pencahayaan di suatu ruangan. Pemilihan warna yang gelap tentunya dapat membuat penggunaan lampu yang lebih besar dibandingkan warna yang lebih terang. Sehingga pemilihan warna cat tembok yang cenderung terang dapat berperan dalam penghematan energy listrik.

Pemerintah sudah menyadari bahwa diperlukan adanya kebijakan nasional yang mengatur tentang energi, karena energi telah menjadi maslalah besar yang dihadapi oleh dunia global beberapa waktu lalu. Peraturan pemerintah Republik Indonesia nomor 79 tahun 2014 tentang Kebijakan Energi Nasional Pasal 6 menyatakan bahwa semua pihak harus memanfaatkan energi secara efisien di semua sektor. Pemilihan warna cat yang sesuai untuk bangunan dapat menekan jumlah konsumsi energi listrik, yang dapat diartikan sebagai salah satu upaya pemanfaatan energi secara efisien.

Semakin terang warna cat yang digunakan terbukti semakin kecil konsumsi energi cahaya lampu pada suatu ruangan. Yohana dan Bayu (2011) mengemukakan penelitian mengenai panas yang tersimpan di dalam ruangan akan lebih besar dengan dinding bagian luar menggunakan cat warna gelap dibandingkan dengan rumah yang dinding bagian luarnya menggunakan cat warna terang. Nilai rata-rata panas yang tersimpan pada rumah menggunakan exhaust fan dengan tanpa cat 10,34 Watt, warna cat putih 6,93 watt, warna cat abuabu 9,56 watt dan warna cat kuning 7,63 watt. Sedangkan panas yang tersimpan pada rumah tanpa menggunakan exhaust fan (secara alami) dengan tanpa cat sebesar 11,79 watt, cat putih 7,00 watt, cat abu-abu 10,83 watt dan warna cat kuning 8,46 watt.

Setelah data emisivitas diperoleh penelitian dilanjutkan dalam proses pembelajaran di SMK Negeri 2 Bengkulu Tengah pada tanggal 24 - 28 April 2017. Hasil penelitian memperoleh data-data sebagai berikut:

\section{1) Rata-rata Pretest dan Postest}

Hasil pretest dan Postest dapat dilihat pada gambar 1 berikut ini: 


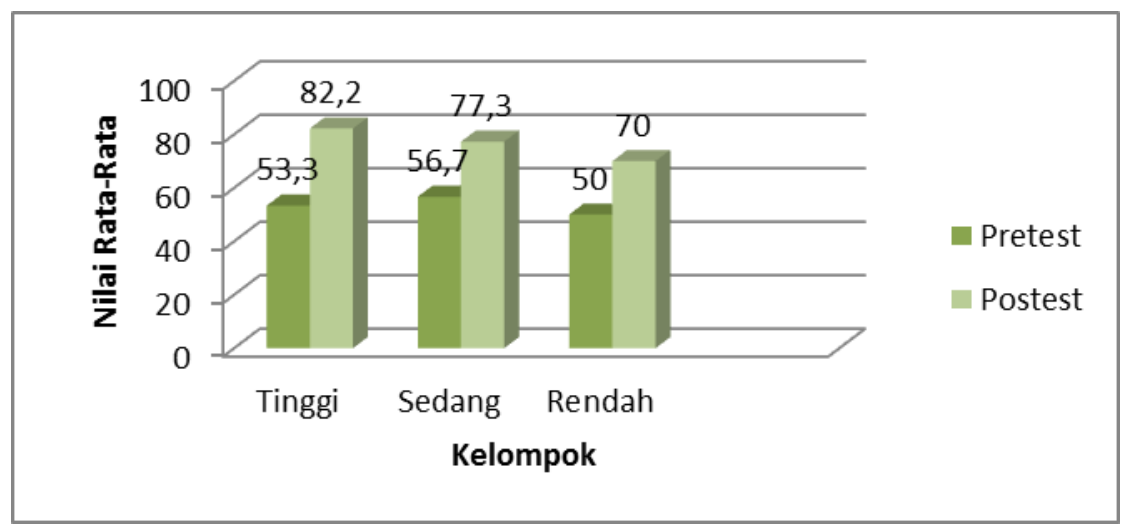

Gambar 1. Grafik nilai rata-rata pretest dan posttest

Dari gambar terlihat masing-masing kelompok mengalami peningkatan hasil belajar kognitif. Kelompok tinggi mengalami kenaikan rata-rata nilai sebesar 28,9; kelompok sedang sebesar 20,6; kelompok rendah sebesar 20,0.

\section{2) Simpangan Baku}

Simpangan baku nilai posttest yang diperoleh dari penelitian sebesar sebesar 8,3 untuk kelompok tinggi, kelompok sedang sebesar 7,9 dan kelompok rendah sebesar 6,3. Hal ini mengindikasikan bahwa kelompok tinggi memiliki sebaran nilai yang lebih tinggi daripada kelompok lainnya.

3) Perhitungan Gain
Tabel 6 menunjukkan bahwa kelompok tinggi memiliki nilai $\mathrm{N}$-gain lebih tinggi dari kelompok lainnya sebesar 0,76 dalam katagori tinggi. Kelompok sedang memiliki nilai $\mathrm{N}$-gain sebesar 0,64 dalam katagori sedang. Kelompok rendah memiliki nilai $\mathrm{N}$ gain paling rendah sebesar 0,46 dalam katagori sedang. Hal ini berarti bahwa kelompok tinggi memiliki peningkatan nilai yang lebih tinggi dari kelompok lainnya.

\section{4) Analisis Inferensial}

Analisis inferensial dalam penelitian ini menggunakan uji ANAVA. Ringkasan perhitungan Anava dapat dilihat pada tabel 3 berikut ini:

Tabel 3. Ringkasan Perhitungan Anava

\begin{tabular}{|c|c|c|c|c|c|c|}
\hline $\begin{array}{l}\text { Sumber } \\
\text { Varians }\end{array}$ & $\begin{array}{l}\text { Jumlah } \\
\text { Kuadrat } \\
\text { (JK) }\end{array}$ & $\begin{array}{l}\text { Derajat } \\
\text { bebas }\end{array}$ & $\begin{array}{l}\text { Kuadrat } \\
\text { Rerata } \\
\text { (KR) }\end{array}$ & $\mathbf{F}_{\text {hitung }}$ & $\begin{array}{l}\text { Taraf } \\
\text { Signifikansi }\end{array}$ & Keputusan \\
\hline $\begin{array}{c}\text { Antar } \\
\text { kelompok }\end{array}$ & 537,78 & 2 & 268,89 & \multirow{3}{*}{4,40} & \multirow{3}{*}{$\begin{array}{c}\alpha=0,05 \\
F_{\text {tabel }}=3,35\end{array}$} & \multirow{3}{*}{$\begin{array}{c}\text { Fhitung }> \\
\text { Ftabel } \\
4,40>3,35 \\
\text { Jadi } \mathrm{H}_{2} \\
\text { diterima } \\
\text { untuk taraf } \\
\text { signifikansi } \\
5 \%\end{array}$} \\
\hline $\begin{array}{c}\text { Dalam } \\
\text { kelompok }\end{array}$ & $1.648,89$ & 27 & 61,07 & & & \\
\hline Total & - & 29 & - & & & \\
\hline
\end{tabular}

Dari perhitungan N-gain diperoleh kesimpulan bahwa masing-masing kelompok mengalami peningkatan hasil belajar. Untuk mengetahui apakah terdapat perbedaan kenaikan hasil belajar siswa kelompok tinggi, sedang dan rendah maka dilakukan uji Analisis Varian (Anava). Uji ANAVA menunjukkan $F_{\text {hitung }}>F_{\text {tabel }}(4,40>$ $3,35)$ pada taraf signifikansi $5 \%$, sehingga $\mathrm{H}_{2}$ diterima. Kesimpulan dari perhitungan anava adalah terdapat perbedaan hasil belajar kognitif siswa pada kelompok tinggi, sedang dan rendah dengan menggunakan model PBL.Sependapat dengan Lia Yunita pada tahun 2016 dengan judul " Efektifitas Problem Based Learning Berbantuan Edmodo untuk Meningkatkan Prestasi Belajar Fisika Studi pada Suhu dan Kalor Kelas X Teknik Kendaraan Ringan SMK Tunas Bangsa Wanareja". Hasil penelitian menunjukan bahwa problem based learning 
berbantuan edmodo efektif dalam meningkatkan prestasi belajar fisika.

Pada proses pembelajaran, fungsi guru hanya sebagai fasilitator, yaitu memberikan bimbingan/pengarahan seperlunya kepada siswa. Keaktifan siswa lebih ditekankan pada proses pembelajaran. Dari penjabaran mengenai hasil penelitian di atas, jelas terlihat bahwa pembelajaran fisika dengan menggunakan model problem based learning mampu meningkatkan hasil belajar siswa. Model problem based learning berkaitan dengan penggunaan kecerdasan dari dalam diri individu yang berada dalam sebuah kelompok atau lingkungan untuk memecahkan masalah yang bermakna, relevan dan kontekstual. Penerapan model ini dalam pembelajaran menuntut kesiapan baik dari pihak guru yang harus berperan sebagai fasilitator sekaligus sebagai pembimbing. Guru dituntut dapat memahami secara utuh dari setiap bagian dan konsep model problem based learning dan menjadi penengah yang mampu merangsang kemampuan berpikir siswa. (Rusman, 2010:247)

\section{KESIMPULAN}

Berdasarkan hasil penelitian dan pembahasan dapat ditarik kesimpulan bahwa: 1) Nilai emisivitas warna ungu (purple comet) adalah 0,91,emisivitas warna hijau (going green) adalah 0,84, emisivitas warna biru (true blue) adalah 0,77 , emisivitas warna merah (talk of the town) adalah 0,66, emisivitas warna hijau muda (apple martini) adalah 0,61, emisivitas warna biru muda (sky blue) adalah 0,54, emisivitas warna jingga (orange torch) adalah 0,50, emisivitas warna coklat muda (pastry puff) adalah 0,46, emisivitas warna kuning (absolute yellow) adalah 0,37, dan emisivitas warna merah muda (crystal pink) adalah 0,24. 2) Terdapat peningkatan hasil belajar pada konsep Perpindahan Kalor siswa kelas $X$ TKR SMK Negeri 2 Bengkulu Tengah kelompok tinggi, sedang, dan rendah. Nilai $\mathrm{N}$-gain untuk kelompok tinggi sebesar 0,76 dalam katagori tinggi, kelompok sedang sebesar 0,64 dalam katagori sedang, dan kelompok rendah sebesar 0,46 dalam katagori sedang. 3)Terdapat perbedaan hasil belajar kognitif siswa pada kelompok tinggi, sedang dan rendah yang ditunjukkan oleh $F_{\text {hitung }}>F_{\text {tabel }} \quad(4,40>3,35)$ pada taraf signifikansi $5 \%$.

\section{DAFTAR PUSTAKA}

Amin, N. 2011. Optimasi Sistem Pencahayaan dengan Memanfaatkan Cahaya Alami (Studi Kasus Lab. Elektronika dan Mikroprosessor UNTAD). 1(1): 43-50. Diakses 3 Agustus 2016

Anambyah, S dan Endang S. 2010. Pengaruh Pewarnaan Beton Cetak Pada Dinding Serap Sebagai Selubung Bangunan Tinggi. ForumTeknik Vol. 33, No. 2, Mei 2010. Diakses 3 Agustus 2016

IIminnafik, N., Digdo L.S., Hary. S., Ade. A. M. M dan Erfani. M. 2015. Variasi bahan dan warna atap bangunanuntuk Menurunkan Temperatur Ruangan akibat Pemanasan Global. Seminar Nasional Tahunan Teknik Mesin XIV (SNTTM XIV). Banjarmasin, 7-8 Oktober 2015. Diakses 29 Juni 2016

Jin, M dan Shunlin L. 2005. An Improved Land Surface Emissivity Parameter for Land Surface Models Using Global Remote Sensing Observations. Journal of Climate. 15 Juni 2006. Diakses 23 Agustus 2016

Lillesand, T. M., Kiefer, R. W. \& Chipman, H. W., 2008. Remote Sensing and Image Interpretation. New York : Sixth ed. John Willey \& Son. Diakses 3 Agustus2016

Peraturan pemerintah Republik Indonesia nomor 79 tahun 2014 tentang Kebijakan Energi Nasional

Rusman. 2010. Model-model Pembelajaran Mengembangkan Profesionalisme Guru. Jakarta: PT Raja Grafiko Persada

Suparno, P. 2013. Metodologi Pembelajaran Fisika Konstruktivistik dan Menyenangkan. Yogyakarta: Universitas Sanata Dharma

Uemoto, K. L., Neide. M. N., Vanderley dan John. S. 2010. Estimating Thermal Performance of Cool Colored Paints. 
http://www.elsevier.com/locate/enbuild. Diakses 9 Juni 2016

Yohana, E dan Bayu N. 2011. Perbandingan Stack Effect pada Rumah secara Konveksi Paksa dan Konveksi Alami Ketika Kondisi Hujan. http://ejournal.undip.ac.id/index.php/rot asi. Diakses 29 Juni 2016
Yunita, L. 2016. Efektifitas Problem Based Learning Berbantuan Edmodo untuk Meningkatkan Prestasi Belajar Fisika Studi pada Suhu dan Kalor Kelas $X$ Teknik Kendaraan Ringan SMK Tunas Bangsa Wanareja. Prosiding Seminar Nasional XI Universitas Proklamasi 45 Yogyakarta. Diakses 2 Juni 2017 